\title{
Research on Islanding Detection of Grid-Connected System
}

\author{
Liu Zhifeng \\ School of Electronic and Electrical Engineering \\ Shanghai University of Engineering Science, SUES \\ Shanghai, China \\ Zhang Liping* \\ School of Electronic and Electrical Engineering \\ Shanghai University of Engineering Science, SUES \\ Shanghai, China
}

\begin{abstract}
This paper proposed a modified detection based on the point of common coupling (PCC) voltage in the three-phrase inverter, combined over/under frequency protection, to achieve the detection of islanding states rapidly. Islanding detection is an common issue existing in distributed generation system. Compared with active islanding detection, this method could detect the islanding quickly and effectively .The simulation and experimental results shows that this new method can detect the islanding phenomenon quickly and accurately, which can meet the requirement of islanding detection standard, which ensure the stability of the system and the power quality recycling to the grid.
\end{abstract}

Index Terms-islanding detection; self-adaptive; active frequency shift; d-q transform

\section{INTRODUCTION}

Islanding effect is also called Islanding phenomenon, the phenomenon is common in the photovoltaic grid-connected generation system. The power grid stop supplying the local load because of the fault or misoperation, however, the power system cannot detect it, still supplying the peripheral load, forming the power island out of the control of power grid.

Islanding effect will lead to serious results, such as disturbing the operation of the electricity system, destroying user devices, even severely endangered the life safety of the staff who is working for lines maintenance. Consequently, whether the condition of islanding can be detected effectively and timely or not is of great significant for the entire gridconnected system.

\section{MEChANISM AND DETECTION METHOD OF THE ISLANDING EFFECT}

In a real world application, the lord of the photovoltaic employs RLC parallel resonance circuit. According to the IEEE Std.929-2000 [1] , the recommended generic system for islanding detection [2] study is shown in Fig.1.

\author{
Chen Yuchen \\ School of Electronic and Electrical Engineering \\ Shanghai University of Engineering Science, SUES \\ Shanghai, China \\ Jia Chunying \\ School of Electronic and Electrical Engineering \\ Shanghai University of Engineering Science, SUES \\ Shanghai, China
}

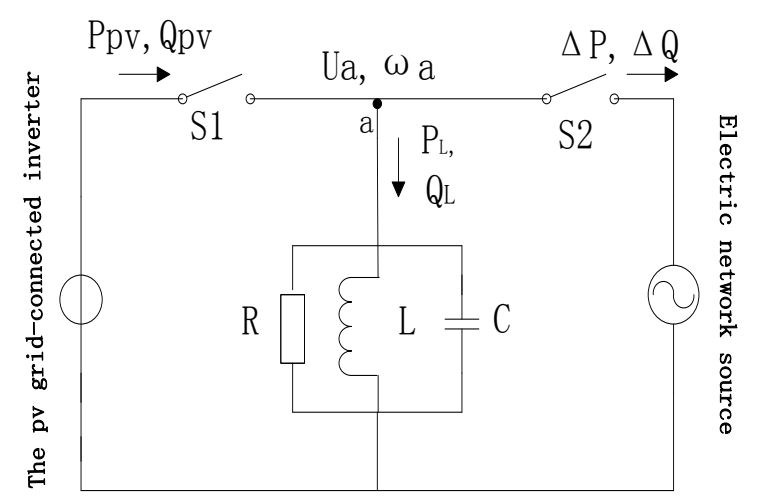

Fig. 1. System for islanding detection study

If the distributed grid-connected generation system works properly, namely

$$
\begin{gathered}
P_{p v}=P_{L}+\Delta P \\
Q_{p v}=Q_{L}+\Delta \boldsymbol{Q} \\
P_{L}=\frac{U_{a}^{2}}{R} \\
Q_{L}=\left(\frac{1}{\omega_{a} L}-\omega_{a} c\right) U_{a}^{2}
\end{gathered}
$$

After the electric network cuts off the power, the photovoltaic grid-connected generation system generate islanding effect [3] , namely

$$
P_{p v}=P_{L}^{\prime}=\frac{U_{a}^{\prime 2}}{R}
$$




$$
Q_{p v}=Q_{L}^{\prime}=\left(\frac{1}{\omega_{a}^{\prime} L}-\omega_{a}^{\prime} c\right) U_{a}^{\prime 2}
$$

Eq (1), (3), (5) indicates that

$$
U_{a}^{\prime 2}=U_{a}^{2}+\Delta P R
$$

$\mathrm{Eq}(2),(4),(6)$ indicates that

$$
\left(\frac{1}{\omega_{a}^{\prime} L}-\omega_{a}^{\prime} c\right) U_{a}^{\prime 2}=\left(\frac{1}{\omega_{a} L}-\omega_{a} c\right) U_{a}^{2}+\Delta P Q
$$

Suppose $U_{a}=U_{a}^{\prime}$, plug (7) into (8), we can obtain:

$$
\left(\omega_{a}-\omega_{a}^{\prime}\right)\left(1+\omega_{a} \omega_{a}^{\prime} L C\right)=\frac{\omega_{a} \omega_{a}^{\prime} L \Delta Q}{U_{a}^{2}}
$$

Where

$U_{a} 、 \omega_{a}$-Voltage and angular frequency of the lord

$P_{p v} 、 Q_{p v}-$ Output active power and reactive power of grid-connected systems

$\Delta P 、 \Delta Q-$ Received active power and reactive power of the grid

$P_{L} 、 Q_{L}-$ Received active power and reactive power of the grid

$\mathrm{Eq}(7)$, (9))indicates that, when the grid-connected generation system can not match with $\Delta \mathrm{P}$, voltage of the load will change; when the grid-connected generation system can not match with $\Delta \mathrm{Q}$, angular frequency will change. If the numerical value is big, voltage and angular frequency of the load exceeds the protected threshold of the overlunder voltage and the overlunder frequency, relay operates cut the connection between the grid-connected generation system and the grid, the grid-connected generation system will stop [4] . Conversely, if the numerical value is small, namely, voltage and frequency of the load changes in permissible range, islanding detection is failed, entering the non-detection zone(NDZ), the system operates in the island state The change threshold of the voltage and frequency of the load can be calculated from (10) and (11) respectively

$$
\begin{gathered}
\left(\frac{U}{U_{\max }}\right)^{2}-1 \leq \frac{\Delta P}{P_{P V}} \leq\left(\frac{U}{U_{\text {min }}}\right)^{2}-1 \\
Q_{\mathrm{f}}\left[1-\left(\frac{f}{f_{\text {min }}}\right)^{2}\right] \leq \frac{\Delta Q_{P_{P V}}}{P_{\mathrm{f}}}\left[1-\left(\frac{f}{f \max }\right)^{2}\right]
\end{gathered}
$$

$U_{\max } 、 U_{\min }-$ The threshold of over/under voltage protection

$$
f_{50 h z} 、 f_{\min }-\text { The threshold of over/under voltage }
$$
protection

$$
Q_{f} \text { - The quality factor of the RLC load. }
$$

Generally, according to whether to add artificial disturbance, there are two ways, passive and active methods. Passive method can complete test by monitoring the output AC voltage by inverter 、 frequency phase、 harmonic instability, before and after the failure of the grid. The primary advantage to this approach is that it has no interference to the grid and the quality of the output electricity. The drawback of this approach is that it has large area of NDZ, when the load can not match with output power of the inverter. Overlunder frequency protection(OFPIUFP), Overlunder voltage protection(OVPIUVP), phase jump detection, voltage harmonic detection 、 active power change rate method . frequency change ratio methods are the most widely used passive islanding detection methods, which determine the islanding condition by measuring the PCC voltage and the current from the DG.

Active methods detect the effect on the line voltage by inject current frequency or phase interference signal in the output stage of the grid-side converter [5].

In the operation state of islanding, disturbance signals will accumulate on the line voltage and outside acceptable tolerances, thus detecting the islanding. Though active methods suffer smaller NDZS, the presence of disturbances during normal operation will sacrifice power quality and reliability of the power system. The sandia frequency drift [6], slip-mode frequency shift are three classical active methods by creating a continuous trend to change the frequency during islanding.

Based on the active islanding detection method for further analysis and comparison, a new and improved detection method is proved, namely, based on the d-q transform adaptive frequency shift(AFD) islanding detection method of the detection principle [7]-[10] , by d-q transform on the point of common coupling(PCC) Voltage in the three-phrase inverter, the output current of the inverter frequency periodic disturbance, combined over/under frequency protection, to achieve rapid detection of islanding states, which ensure the stability of the system and the power quality recycling to the grid.

\section{THE OPERATING PRINCIPLE OF AFP Method}

\section{A. AFD method}

AFD is the most common method in the active islanding detection. The control flow of this method is presented in Fig 2.

Where

$$
f_{50 h z}: \text { the frequency of the grid voltage. }
$$




\section{$f_{\text {inv }}$ :the output voltage frequency of the inverter}

$\Delta f:$ the set value of frequency perturbation in the control system

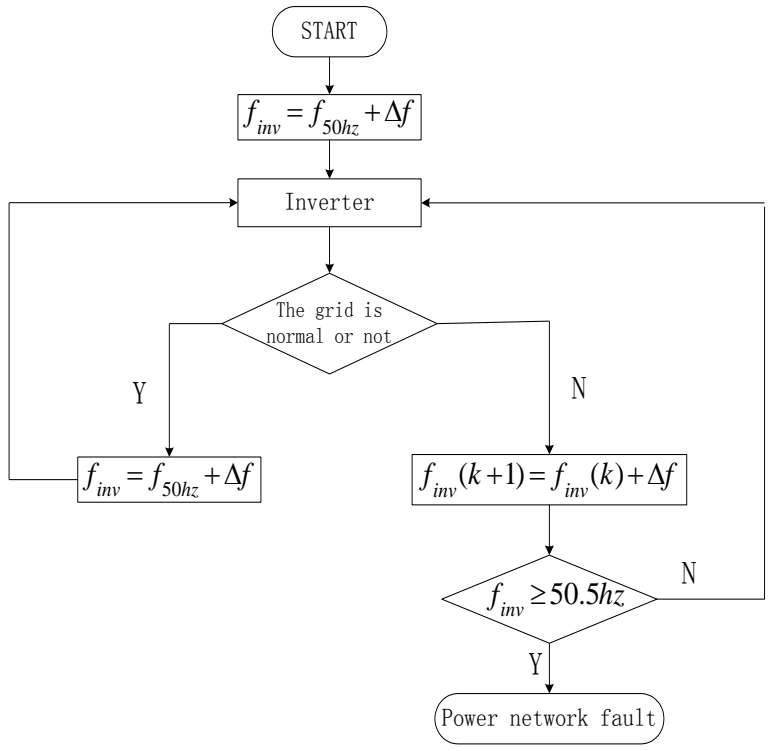

Fig. 2. Flowchart of the AFD method

Active frequency drift method works as follows:

Firstly, there are certain errors- $\Delta \mathrm{f}$, between the frequency of the output voltage and the grid voltage through the control of the inverter. Secondly, $\Delta \mathrm{f}$ is always within a narrow range because of the corrective action in the phase-locked loops circuit, when the grid operates properly [11]. Thirdly, the output voltage frequency of the inverter $\mathrm{f}_{\text {inv }}$ will change, when the grid failure. At the following power frequency periodic of the inverter, based on the $f_{\text {inv, }}$, adding the set value of frequency perturbation to control the output voltage frequency of the inverter. It leads to the increasement of errors between output voltage frequency and the grid voltage frequency. The cycle continues after this, until output voltage frequency of triggering protection circuit [12], cutting the connection between inverter and the grid.

Fig 3 illustrate the waveform of the perturbation frequencies using AFD method. The curve describe the wave of current and interference signal in one power frequency periodic, plotted by time on the horizontal axis and per unit value of current on the vertical. The relations are as follows:

$$
c f=t_{z} / T_{\text {grid }}
$$

Where

$t_{z}$ : The period of the voltage value is zero.

$T_{\text {grid }}$ : A half cycle of the fundamental voltage

\section{B. The shortage of AFD method}

As presented in [13], if the islanding occurs in the gridconnected generation system. There will be a much smaller
NDZS using AFD method than using passive detection methods. Once the value of $\mathrm{cf}$ is too small, compared with the traditional voltage frequency detection method, AFD method can not highlight its superiority; however, when the cf exceed the permitted value, the distortion ratio of current harmonic on $\mathrm{AC}$ grid side will increase, harmonics will affect the power quality recycling to the grid seriously. Therefore, NDZS in the AFD [14] would still need to be reduced in order to satisfy the increasing harsh conditions of the grid.

When the system load does not conform to (1), the system frequency will always beyond the normal range of work in theory. But, there is a time limit on detecting the islanding, especially the use of the automatic reclosing at present. If the detecting speed is too slow, the grid-connected generation system is not completely cut off before the automatic reclosing recloses again, it is very likely to make considerable oscillation, leading to accidents. Such a scenario may be typically in the AFD method, for example when the load is inductive, there is a trend that the phase of voltage is prior to current, the frequency of value will keep rising based on the assumption that without using AFD method, when the islanding happens [15]. However, if the value of $\mathrm{cf}$ is fixed in the AFD method, mitigating voltage frequency change, but tend to delay the trip time, and vice versa.

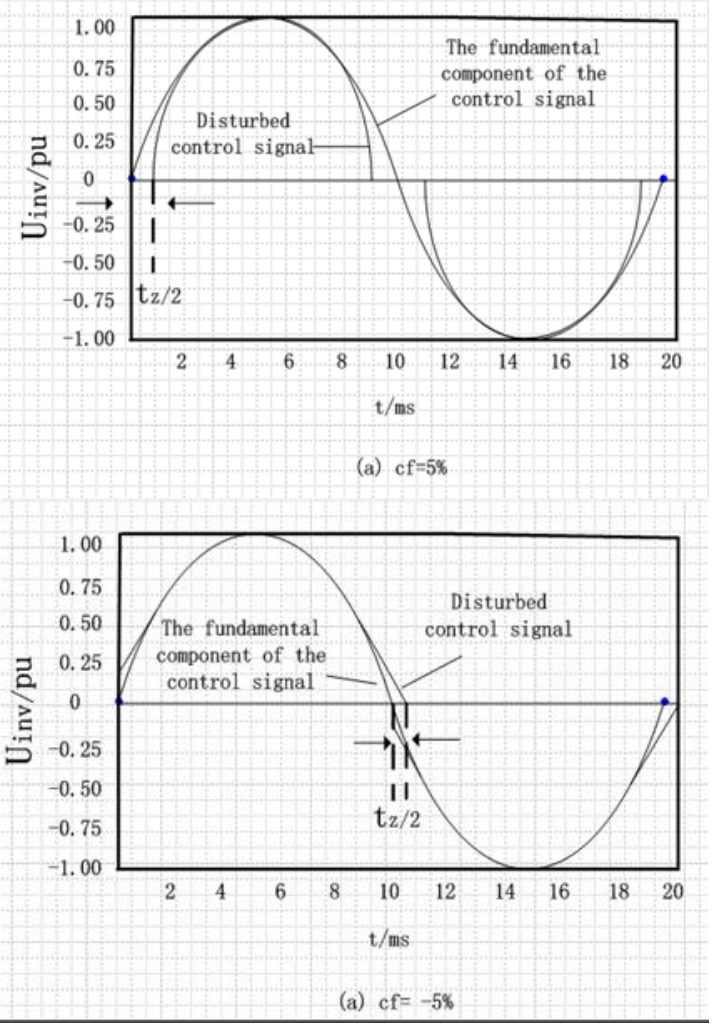

Fig. 3. Waveform of the perturbation frequencies using AFD method

\section{Adaptive Acive Frequency Shift Islanding Detection Based on the d-q Transform}

For overcoming the shortcomings of AFD method for islanding detection ,the detection algorithm of AFD method needs to be improved, convert the output current frequency disturbance of the inverter within single-phase into three-phase 
grid-connected system. The new islanding detection algorithmadaptive active frequency shift islanding detection based on the d-q transform will be available.

This method using the angle frequency after d-q transform in the positive feedback form at frequency disturbance. In this way, it will cause the three-phase output current frequency disturbance, achieving the adaptive active frequency shift islanding detection [16]-[18],Adaptive active frequency shift based on the d-q transform shown in the Fig 4.

Essentially, adaptive active frequency shift based on the d-q transform complete the control of islanding through the feedback structure. It refers to under the condition of different frequencies of inverter, using different methods to change the output current frequency [19] . The PCC voltage frequency is detected in every cycle, when the PCC voltage frequency exceed the normal frequency of the grid voltage-50hz, by applying a positive disturbance to the current frequency:

$$
f_{i}=f_{u p}+\Delta f
$$

Conversely, if the PCC voltage frequency is less than 50hz, by applying a negative disturbance to the current frequency:

$$
f_{i}=f_{u p}-\Delta f
$$

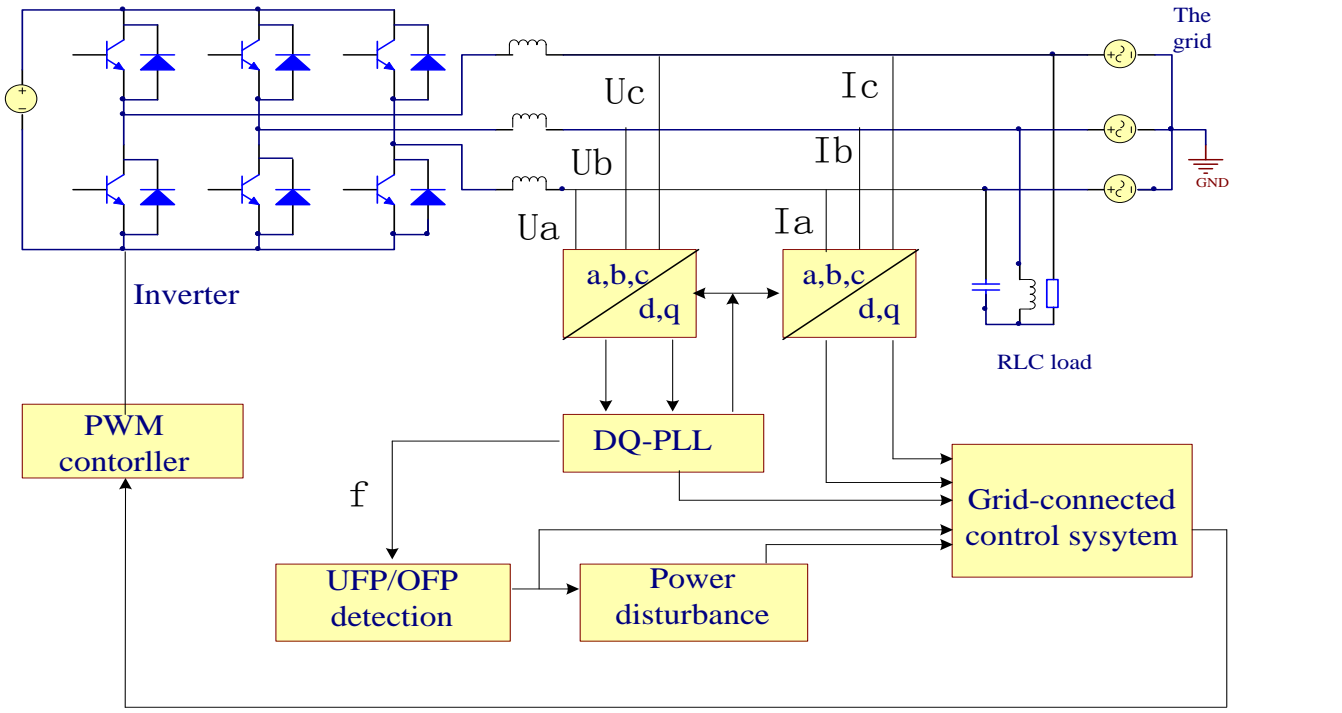

Fig. 4. Structure of improved design of is landing detection

Current frequency will take similar periodic disturbance, with the positive feedback control. The special algorithm processes are as follows:

$$
f_{i}=\left\{\begin{array}{l}
f_{u p}+\Delta f, f_{u p} \geq 50 h z \\
f_{u p}+k n\left(f_{u p}-50\right), f_{u p} \leq 50 h z
\end{array}\right.
$$

Where

$$
\begin{aligned}
& f_{i}: \text { Output current frequency of inverter } \\
& f_{u p}: \text { Frequency of PCC voltage }
\end{aligned}
$$

$\mathrm{n}$ : Positive feedback factor

$\mathrm{k}$ : Ratio coefficient

\section{$\Delta f:$ Added frequency disturbance}

During closing the switch of gird-connected, because of the clamp effect of the grid frequency, The PCC voltage frequency follows the grid frequency. Although there are disturbances of current frequency during partial periodical, output current of the inverter, reset at the zero crossing point of the grid voltage, started with another sinusoidal. However, once the switch of the grid-connected is off, without the clamp effect of the grid frequency, the PCC voltage will follow the change of the inverter output voltage [20] .

Because of the effect of local load, the PCC voltage frequency will change accordingly, beyond the threshold value of frequency protection within the passive islanding detection, thus detect the islanding.

\section{Simulation RESUlts}

In the end, the simulation model is put up using Matlab/Simulink. The output current of inverter is programmed in the S-Function module by using periodic frequency disturbance. Namely, add the adaptive active frequency shift based on the d-q transform, combined over/under frequency protection, to achieve rapid detection of islanding states. Threephase grid voltage is $380 \mathrm{~V}$,grid frequency is $50 \mathrm{hz}$, the threshold value of frequency protection is $(50+0.5) \mathrm{hz}$.

According to the GB/T15945-1995, the allowable range of grid voltage frequency is $0.2 \mathrm{hz}$, thus the value of it is $0.2 \mathrm{hz}$. In the simulation, the value of $\Delta \mathrm{f}$ and $\mathrm{k}$ is $0.5 \mathrm{hz}$, and 5 , respectively. The initial value of $n$ is zero, increased by 2 every a periodical, increased frequency for quick detection. Continuous frequency perturbation for 3 cycles is added in the same algorithm every five periodicals. Select the balanced resonant load under the testing standard of islanding. In the load of the parallel RLC load, in order to achieve the 
appropriate value of the quality factor- 2.5 , the value of $\mathrm{L}, \mathrm{C}$ and $\mathrm{R}$ will be $61.5 \mathrm{mh}, 164.4 \mu \mathrm{f}, 48.39 \Omega$, respectively.

The simulation waveform are presented in Fig.3. It can be seen from the Fig5 that: the voltage wave of A-phase and gridconnected current without the adaptive active frequency shift based on the d-q transform. As the balanced load, the change of the current and voltage amplitude is very small, after disturbing electrical grids when the value of time is $50 \mathrm{~ms}$. Using only OFP/UFP method can not detect the islanding. It can be seen from the Fig6 that: the output waveform of the current frequency.

Conversely, adding the adaptive active frequency shift based on the d-q transform to the islanding detection method, the frequency would drop off, until the value of frequency out of the threshold range of frequency protection, thus detect the islanding, meeting the testing time standard of islanding regulated by IEEEstd.1547.
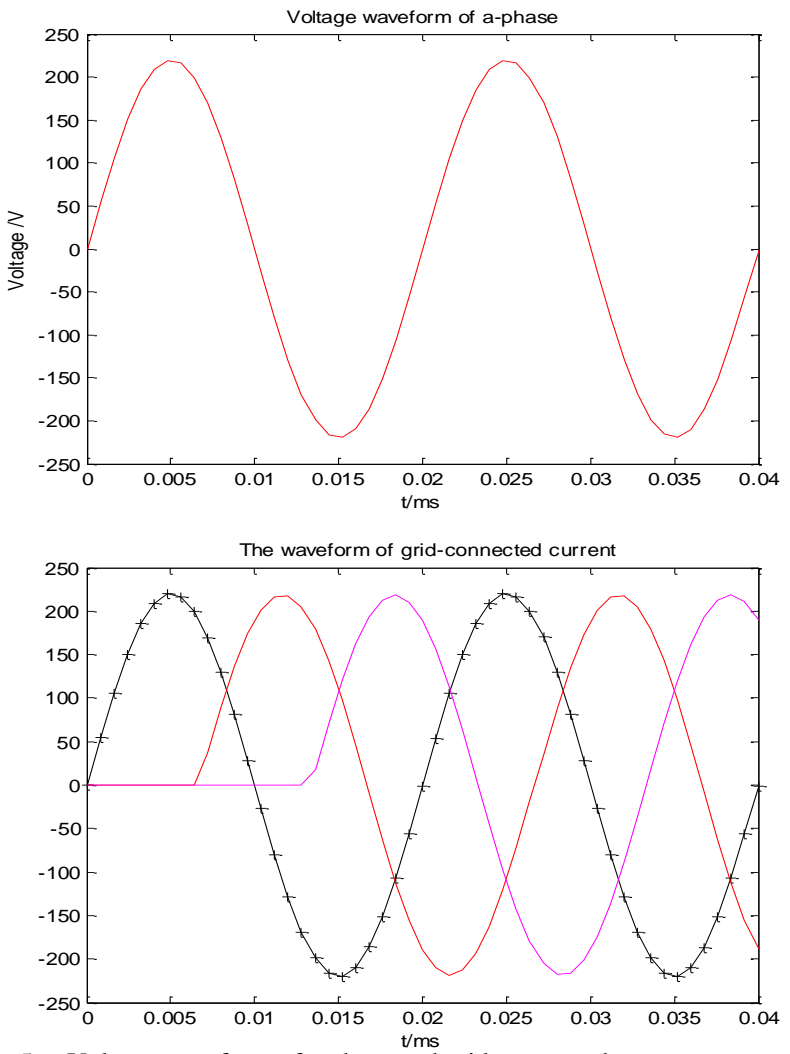

Fig. 5. Voltage waveform of a-phase and grid-connected current

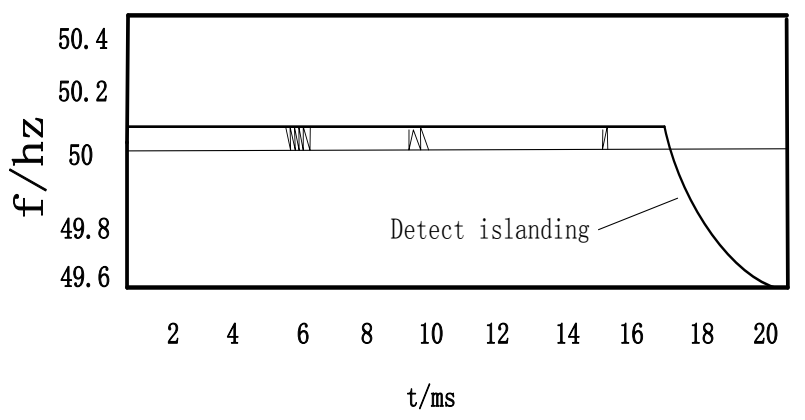

Fig. 6. Output waveform of the current frequency

\section{CONCLUSION}

This paper proposed a modified detection based on the point of common coupling (PCC) voltage in the three-phrase inverter, combined over/under frequency protection. The simulation results shows that this new method can detect the islanding phenomenon quickly and accurately, which can meet the requirement of islanding detection standard, which ensure the stability of the system and the power quality recycling to the grid.

\section{ACKNOWLEDGMENT}

First and foremost, I would like to show my deepest gratitude to my supervisor, Prof. Zhang liping, a respectable, responsible and resourceful scholar, who has provided me with valuable guidance in every stage of the writing of this paper. Without her enlightening instruction, impressive kindness and patience, I could not have completed my paper. Her keen and vigorous academic observation enlightens me not only in this paper but also in my future study.

\section{REFERENCES}

[1] H. B. Puttgen, P. R. MacGregor, and F. C. Lambert, "Distributed generation: Semantic hype or the dawn of a new era?," IEEE Power Energy Mag., vol. 1, no. 1, pp. 22-29, Jan./Feb. 2003.J. Clerk Maxwell, A Treatise on Electricity and Magnetism, 3rd ed., vol. 2. Oxford: Clarendon, 1892, pp.68-73.

[2] P. P. Barker and R. W. de Mello, "Determining the impact of distributed generation on power systems: Part 1-Radial distribution systems," in Proc. IEEE Power Eng. Soc. Summer Meeting, Jul. 2000, pp. 16451656.

[3] IEEE Recommended Practice for Utility Interface of Photovoltaic (PV) Systems, IEEE Standard 929-2000, Apr. 2000R. Nicole, "Title of paper with only first word capitalized," J. Name Stand. Abbrev., in press.

[4] IEEE Standard for Interconnecting Distributed Resources with Electric Power Systems, IEEE Standard 1547-2003, Jul. 2003.M. Young, The Technical Writer's Handbook. Mill Valley, CA: University Science, 1989.

[5] I. J. Balaguer, Q. Lei, S. T. Yang, U. Supatti, and F. Z. Peng, "Control for grid-connected and intentional islanding operations of distributed power generation," IEEE Trans. Ind. Electron., vol. 58, no. 1, pp. 147157, Jan. 2011.

[6] R. A. Walling and N. W. Miller, "Distributed generation islandingImplications on power system dynamic performance," in Proc. IEEE Power Eng. Soc. Summer Meeting, Jul. 2002, pp. 92-96.

[7] A. Timbus, A. Oudalov, and N. M. Ho Carl, "Islanding detection in smart grids," in Proc. IEEE Energy Convers. Congr. Expo., Sep. 2010, pp.3631-3637.

[8] F. De Mango, M. Liserre, A. D. Aquila, and A. Pigazo, "Overview of antiislanding algorithms for PV systems. Part I: Passive methods," in Proc.IEEE Power Electron. Motion Control Conf., Aug. 2006, pp. 18781883.

[9] Z. Ye, A. Kolwalkar, Y. Zhang, P. Du, and R. Walling, "Evaluation of antiislanding schemes based on nondetection zone concept," IEEE Trans.Power Electron., vol. 19, no. 5, pp. 1171-1176, Sep. 2004.

[10] F. De Mango, M. Liserre, and A. D. Aquila, "Overview of anti-islanding algorithms for PV systems. Part II: Active methods," in Proc. IEEE Power

[11] J. H. Kim, J. G. Kim, Y. H. Ji, Y. C. Jung, and C. Y. Won, "An islanding detection method for a grid-connected system based on the Goertzel algorithm," IEEE Trans. Power Electron., vol. 26, no. 4, pp. 1049-1055,Apr.2011.

[12] H. Karimi, A. Yazdani, and R. Iravani, "Negative-sequence current injection for fast islanding detection of a distributed resource unit,"

[13] A. Yafaoui, B. Wu, and S. Kouro, "Improved active frequency drift antiislanding detection method for grid connected photovoltaic 
systems,"IEEE Trans. Power Electron., vol. 27, no. 5, pp. 2367-2375, May,2012.

[14] L. A. C. Lopes and H. L. Sun, "Performance assessment of active frequency drifting islanding detection methods," IEEE Trans. Energy Convers.,vol.21,no.1,pp.171-180,Mar.2006

[15] H. Vahedi and M. Karrari, "Adaptive fuzzy Sandia frequency-shift method for islanding protection of inverter-based distributed generation," IEEE Trans. Power Del., vol. 28, no. 1, pp. 84-92, Jan. 2013.

[16] G. A. Kern, "SunSine300, utility interactive AC module anti-islanding test results," in Proc. 26th IEEE Power Photovoltaic Spec. Conf., Sep. 1997,pp. 1265-1268

[17] E. J. Estebanez, V. M. Moreno, A. Pigazo, M. Liserre, and A.
DellAquila,"Performance evaluation of active islanding - detection algorithms in distributed-generation photovoltaic systems: Two inverters case," IEEE Trans. Ind. Electron., vol. 58, no. 4, pp. 1185-1193, Apr. 2011

[18] L. A. C. Lopes and Y. Z. Zhang, "Islanding detection assessment of multiinverter systems with active frequency drifting methods," IEEE Trans.PowerDel.,vol.23,no.1,pp.480-486,Jan.2008.

[19] M. A. Kashem and G. Ledwish, "Distributed generation as voltage support for single wire earth return systems," IEEE Trans. Power Del., vol.19,no.3,pp.1002-1011,Jul.2004.

[20] H. H. Zeineldin, "A Q-f droop curve for facilitating islanding detection of inverter-based distributed generation," IEEE Trans. Power Electron.,vol. 24, no. 3, pp. 665-673, Mar. 2009. 